\title{
Bound nicotinic acid in dietary wheaten products
}

\author{
BY K. MARY CLEGG \\ Department of Food Science, Royal College of Science and Technology, Glasgow
}

(Received 20 November 1962-Revised I4 March 1963)

In cereals, nicotinic acid occurs mainly in a bound form, niacytin, which is nutritionally unavailable to certain bacteria and mammals (Kodicek \& Wilson, I960). Most published findings relating to nutritional availability have been on rats and pigs, and the results have been in agreement with microbiological assays (Braude, Kon, Mitchell \& Kodicek, I955; Kodicek, Braude, Kon \& Mitchell, I956, I959; Kodicek \& Wilson, I959; Kodicek, I960; Carpenter, Kodicek \& Wilson, I960; Chaudhuri \& Kodicek, I960). It is known that the nicotinic acid metabolism of pigs is similar to that of man, although there is no direct evidence about the availability of the bound form to man.

In Britain, $20-30 \%$ of the total dietary nicotinic acid intake comes from cereals, and it therefore seemed of interest to establish the nutritional availability of the vitamin from this source. It is known that bound nicotinic acid is liberated by treatment of the cereal with dilute alkali. My investigation was undertaken to find the percentage of free nicotinic acid, determined by microbiological assays, in wheat constituents of the human diet. The survey was made on brown breads, wheaten scones, 'digestive' biscuits and wheaten breakfast cereals. These products all contain a high proportion of the bran and aleurone fractions, which in turn contain about $85 \%$ of the nicotinic acid of the wheat grain. White-flour products are of less interest, since compulsory fortification results in so high a free nicotinic acid level that the bound form of the vitamin can be of little nutritional significance.

\section{EXPERIMENTAL}

\section{Materials}

The same sample of commercial wholemeal flour was used to prepare all the test scones according to the basic recipe: $100 \mathrm{~g}$ wholemeal flour, $\frac{1}{2} \mathrm{egg}+$ milk $(=60 \mathrm{ml})$, $25 \mathrm{~g}$ margarine, a pinch of salt, and sodium bicarbonate or commercial baking powder. In the first series, $\mathrm{NaHCO}_{3}$ was well mixed into the flour at a level of $3 \cdot 5,2 \cdot 0, \mathrm{I} \cdot 5$, $\mathrm{I} \cdot 0,0.75$ or $0.5 \mathrm{~g} / \mathrm{l} 00 \mathrm{~g}$ flour; also, scones were made with $3.5 \mathrm{~g}$ commercial baking powder/roo $\mathrm{g}$ flour. The dough was rolled out to a thickness of about $0.5 \mathrm{in}$. and cut into rounds of 2 in. diam. The scones were baked at $265^{\circ}$ for $10 \mathrm{~min}$. In a second series, dough containing $0.75 \mathrm{~g} \mathrm{NaHCO}_{3} / 100 \mathrm{~g}$ flour was prepared in the same way, but the scones were baked at $265^{\circ}$ for $5,7,15$ or $20 \mathrm{~min}$. The same sample of flour was used to bake two loaves of bread; both were baked at $215^{\circ}$ for $35 \mathrm{~min}$, but one was prepared by chemical aeration and included a little fat, skim-milk powder and 
baking powder, and the other by the usual yeast fermentation. Further, samples of wheaten scones, brown bread, 'digestive' biscuits and wheaten breakfast cereals were bought locally.

The $\mathrm{pH}$ of aqueous extracts of each test material was determined with a $\mathrm{pH}$ meter (Cambridge Instrument Co. Ltd).

\section{Microbiological technique}

The method of Clegg, Kodicek \& Mistry (1952), incorporating the use of an internal nicotinic acid standard, was used for the microbiological assay, with Lactobacillus case $i$ as the test organism. A weak acid extract of the test material was prepared; this extract contained both free and bound nicotinic acid, but the microbiological analysis measured only the free form. A measured portion of the acid extract was treated with $\mathrm{N}-\mathrm{NaOH}$ to liberate the bound nicotinic acid, and assay of this solution gave the total nicotinic acid content of the test material. The difference between the two analyses was a measure of the bound nicotinic acid. The extracts were prepared as described below.

Samples of $2-4 \mathrm{~g}$ were extracted with $50 \mathrm{ml} \mathrm{O} \cdot \mathrm{I} \mathrm{N}-\mathrm{HCl}$ on a boiling water-bath for 30 min. After cooling, the solution was adjusted to $\mathrm{pH}_{3.5}$ with $0.1 \mathrm{~N}-\mathrm{NaOH}$; it was stirred all the time to avoid any localized alkalinity. The extract was made up to $100 \mathrm{ml}$ and filtered, and a measured volume was washed with an equal volume of chloroform. A known volume of the fat-free extract was adjusted to $\mathrm{pH} 6.5$ and diluted to contain about $0.03 \mu \mathrm{g}$ free nicotinic acid/ml. This solution was added aseptically to the previously sterilized tubes containing medium and the internal nicotinic acid standard; this procedure safeguarded against possible liberation of the bound nicotinic acid during autoclaving in the presence of the medium. Another measured portion of the fat-free extract was digested with $\mathrm{N}-\mathrm{NaOH}$ on a boiling waterbath for $30 \mathrm{~min}$; after the $\mathrm{pH}$ had been adjusted to 6.5 , the solution was diluted to contain $0.03 \mu \mathrm{g}$ total nicotinic acid $/ \mathrm{ml}$. This extract was added to the tubes containing internal standard and medium before autoclaving.

In calculating the percentage of bound nicotinic acid in the bread samples, no allowance has been made for the contribution of the free vitamin from the yeast which supplied about $8 \%$ of the total nicotinic acid content; this simplification does not alter the findings to any extent. In the experimental wholemeal scones, the milk and egg made a negligible contribution to the nicotinic acid present. Similarly, the commercial samples were unlikely to contain ingredients that contributed to the nicotinic acid present.

\section{RESULTS}

In the test sample of wholemeal flour $77 \%$ of the total nicotinic acid was present in the bound form, and the $\mathrm{pH}$ value was $5 \cdot 9$. The scones prepared from this flour contained decreasing amounts of $\mathrm{NaHCO}_{3}$ in the first trial and had $\mathrm{pH}$ values ranging from 9.6 to 6.82 . Over this range of $\mathrm{pH}$ the relationship with the percentage of nicotinic acid in the bound form was approximately linear, as shown in Fig. I.

The effect of increasing the period of baking on the liberation of bound nicotinic 
acid from scones containing $0.75 \mathrm{~g} \mathrm{NaHCO}_{3} / \mathrm{roo} \mathrm{g}$ flour is shown in Table $\mathrm{r}$. The effect of heat could not be established as an independent factor, because it was found that the $\mathrm{pH}$ of the scones decreased slightly with increased baking time. Baking for more than to min caused a greater reduction in the percentage of bound nicotinic acid, although these scones were a little less alkaline. Thus, both heat treatment and the alkalinity of the product contributed to the liberation of bound nicotinic acid.

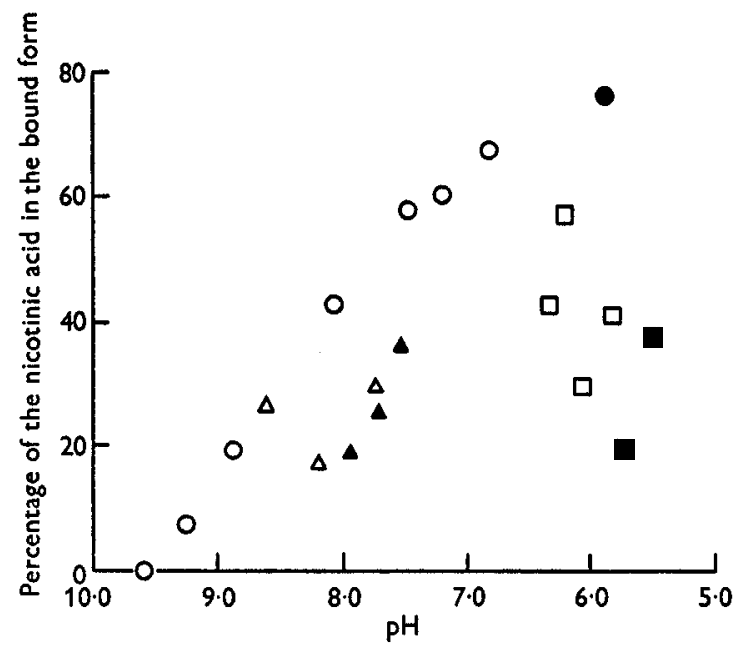

Fig. I. Percentage of the nicotinic acid in the bound form and $\mathrm{pH}$ of test wholemeal scones, with decreasing $\mathrm{NaHCO}_{3}$ content, baked at $265^{\circ}$ for $10 \mathrm{~min}$, and of commercial wheaten products. $\odot$, wholemeal scones; $\bullet$, wholemeal flour; $\Delta$, 'digestive' biscuits; $\Delta$, wheaten

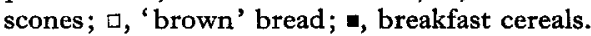

Table I. Percentage of the nicotinic acid in the bound form and $p H$ of experimental wholemeal scones containing $0.75 \mathrm{~g} \mathrm{NaHCO} / 100 \mathrm{~g}$ flour and baked at $265^{\circ}$ for various lengths of time

$\begin{array}{lccc}\text { Material } & \begin{array}{c}\text { Time of baking } \\ (\mathrm{min})\end{array} & \mathrm{pH} & \begin{array}{c}\text { Nicotinic acid } \\ \text { in the bound form } \\ (\%)\end{array} \\ \text { Dough } & - & 7 \cdot 08 & 61 \cdot 9 \\ \text { Scones } & 5 & 7 \cdot 67 & 57 \cdot 0 \\ & 7 & 7 \cdot 66 & 56 \cdot 0 \\ & \text { I0 } & 7 \cdot 48 & 58 \cdot 0 \\ & \text { I5 } & 7 \cdot 20 & 50 \cdot 2 \\ & 20 & 7 \cdot 10 & 47 \cdot 0\end{array}$

The two loaves of bread, prepared by chemical aeration or yeast fermentation from the same sample of wholemeal flour, had $\mathrm{pH}$ values of 6.9 and 6.0 and contained $5^{6}$ and $60 \%$ of the nicotinic acid in the bound form, respectively. As the bread was slightly acidic, the decrease in the percentage of bound nicotinic acid compared with that in the original flour was probably due to the effect of heat during baking.

The $\mathrm{pH}$ values and percentages of bound nicotinic acid of various commercial wheat products are also shown in Fig. 1. In nearly all materials the percentage of bound nicotinic acid was lower than might be expected from the $\mathrm{pH}$ of the product. 
Commercial brown-bread samples, with their variable contents of white flour, were found to contain $30-58 \%$ of the nicotinic acid in the bound form and to be within the $\mathrm{pH}$ range $5 \cdot 8-6 \cdot 4$. The breakfast cereals, bran and puffed wheat, with $\mathrm{pH}$ values of 5.7 and 5.5 , contained only 20 and $38 \%$ respectively of the nicotinic acid in the bound form; it was thought that severe heat treatment must have permitted a breakdown of the naturally occurring niacytin during their manufacture, but it was subsequently learned that the bran had been fortified with nicotinic acid. The wheaten scones were more alkaline than the brown bread or breakfast cereals, with $\mathrm{pH}$ values between $7 \cdot 5$ and $8 \cdot 0$, but the percentage of the nicotinic acid bound was less than in the experimental wholemeal scones of similar alkalinity; again, the dilution of the wholemeal flour with some fortified white flour is a possible explanation. The 'digestive' biscuits were the most alkaline product tested and were within the $\mathrm{pH}$ range $7 \cdot 7-8 \cdot 6$; the bound nicotinic acid content of one sample was in agreement with the experimentally established relationship for the $\mathrm{pH}$ and bound nicotinic acid content of wholemeal scones, but the other two samples had a lower percentage of the nicotinic acid in the bound form, which could be due to dilution of the flour or to the more severe baking conditions.

When some of the extracts were subjected to paper chromatographic analysis (Kodicek \& Reddi, 195I) in an attempt to identify nicotinic acid in the bound and free forms, no satisfactory results were obtained, because the level of nicotinic acid was too low; concentration of the extracts might have led to the breakdown of the niacytin complex.

\section{DISCUSSION}

Many workers have drawn attention to the possibility of nicotinic acid deficiency occurring in communities dependent on cereals for a source of this vitamin, although the total nicotinic acid intake is above the minimum requirement; this situation is especially true of those maize-eating populations who do not treat the maize with lime-water before baking.

It is known that pigs and $L$. case $i$ are unable to utilize the niacytin complex, and that the nicotinic acid metabolism of a pig is similar to that of man, so that the findings in microbiological experiments could apply to man. The microbiological results reported in this paper show that under experimental conditions the percentage of nicotinic acid in the bound form in wholemeal scones and bread was related to the $\mathrm{pH}$ and to the heat treatment of the product. Test scones made with baking powder, or less than $\mathrm{I} \cdot 0 \mathrm{~g} \mathrm{NaHCO}_{3} / \mathrm{roo} \mathrm{g}$ flour, contained $55^{-60} \%$ of the nicotinic acid in the bound form. The experimental wholemeal bread was just acidic, but had had a more severe heat treatment $\left(215^{\circ}\right.$ for $\left.35 \mathrm{~min}\right)$ than the scones; the preparation of bread by the usual fermentation procedure or by the chemical aeration technique resulted in products with about the same percentage of nicotinic acid in the bound form, and similar to that of the slightly alkaline scones.

All the commercial samples of wheaten scones and brown bread, and two of the biscuits had a lower percentage of nicotinic acid in the bound form than experimental wholemeal products with similar $\mathrm{pH}$ values. This finding probably can be attributed 
to the fact that they contained flour fortified with crystalline nicotinic acid. Similarly, the percentage of bound nicotinic acid was low in the two breakfast cereals, of which one, the bran product, was also known to have been fortified.

Carpenter et al. (1960) have shown that a small amount of bound nicotinic acid may be released by boiling in water at neutral $\mathrm{pH}$. Therefore a small reduction in bound nicotinic acid in the baked products compared with the original flour is to be expected, even in absence of alkaline conditions.

The findings of the investigation lend further support to the view that the numerical values given in food tables do not necessarily represent nutritional values. It is recommended that, when calculations of dietary nicotinic acid are made on unfortified wheaten products, it be assumed that half of the total nicotinic acid is nutritionally unavailable.

\section{SUMMARY}

I. The percentage of nicotinic acid in the bound form, determined by microbiological assay with Lactobacillus casei, has been investigated in a series of test wholemeal scones containing decreasing amounts of sodium bicarbonate. A nearly linear relationship was found between the $\mathrm{pH}$ of the scone, over the range $9 \cdot 6-6 \cdot 8$, and the percentage of the nicotinic acid that was bound; scones with a high bicarbonate content and $\mathrm{pH}$ value of $9 \cdot 6$ contained no nicotinic acid in the bound form.

2. The effect of heat on the release of nicotinic acid from the bound form was investigated by baking a scone dough of $\mathrm{pH} 7 \cdot \mathbf{I}$ for increasing lengths of time. Under the experimental conditions there was a decrease in the percentage of bound nicotinic acid when the baking time exceeded $10 \mathrm{~min}$.

3. The percentage of bound nicotinic acid in a range of commercial wheaten foods was investigated in relation to the $\mathrm{pH}$ values of the products. In most samples the percentage of bound nicotinic acid was lower than in experimental wholemeal scones of equivalent alkalinity. Possible explanations of this discrepancy are discussed.

\section{REFERENCES}

Braude, R., Kon, S. K., Mitchell, K. G. \& Kodicek, E. (1955). Lancet, 268, 898.

Carpenter, K. J., Kodicek, E. \& Wilson, P. W. (1960). Brit. F. Nutr. 14, 25.

Chaudhuri, D. K. \& Kodicek, E. (1960). Brit. F. Nutr. 14, 35.

Clegg, K. M., Kodicek, E. \& Mistry, S. P. (1952). Biochem. F. 50, 326.

Kodicek, E. (1960). Brit. F. Nutr. 14, 13.

Kodicek, E., Braude, R., Kon, S. K. \& Mitchell, K. G. (1956). Brit. F. Nutr. 10, 5 I.

Kodicek, E., Braude, R., Kon, S. K. \& Mitchell, K. G. (1959). Brit. F. Nutr. 13, 363.

Kodicek, E. \& Reddi, K. K. (I95I). Nature, Lond., 168, 475 .

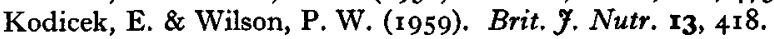

Kodicek, E. \& Wilson, P. W. (1960). Biochem. F. 76, 27 P. 